Keine Panik, aber ...

\title{
Ultraschallgeräte: Die Frist läuft aus!
}

Der Countdown läuft. Ärzte, die Ultraschalluntersuchungen als GKV-Leistung abrechnen und eine Ultraschallgenehmigung für ihre Geräte haben, müssen ihrer KV bis zum 31. März die Geräteeigenschaften melden.

So verlangt es die neue Ultraschallverordnung, die seit April 2009 in Kraft ist. Genauer heißt das, sie müssen der KV den Typ und das Baujahr des Geräts mitteilen. Denn die neue Vereinbarung hat den Ärzten hierfür eine Frist von zwölf Monaten gegeben. Wer die Informationen nicht mehr griffbereit hat, sollte sich an den Hersteller wenden.

Das wird bei vielen Ärzten wohl ohnehin spätestens dann nötig sein,

\section{EUR Schadenersatz Stadtplan-Klau kommt teuer}

\begin{abstract}
Ärzte, die auf ihrer Homepage eine Wegbeschreibung zur Praxis hinzufügen möchten, sollten nicht einfach auf Kartenmaterial aus dem Internet zugreifen bzw. dieses kopieren. Denn das kann teuer werden.
\end{abstract}

Die Besitzerin eines Gästehauses hatte einen Stadtplan von einem kartographischen Verlag im Internet kopiert, um Kunden den Weg zu der Unterkunft zu beschreiben. Der Verlag bemerkte dies und forderte eine Unterlassungserklärung und 650 EUR Schadenersatz plus eine Bearbeitungspauschale von 79 EUR.

Die Gästehausbesitzerin gab die Unterlassungserklärung ab, bezahlte aber lediglich 238 EUR, da entsprechendes Kartenmaterial anderweitig wenn sie nachweisen müssen, dass ihr Ultraschallsystem die technischen Mindestanforderungen, die die neue Verordnung vorschreibt, erfüllt. Für Geräte, die bereits in Betrieb sind, muss dieser zweite Nachweis bis zum 31. März 2013 erbracht sein. Dazu sollten Ärzte - wenn das technische Datenblatt des Geräts nicht vorliegt - eine Garantieerklärung des Geräteherstellers anfordern.

\section{Gnadenfrist fürs Altgeråt}

Grund zur Panik ist die erste Meldepflicht, die nun bald ausläuft, allerdings nicht. Selbst wenn ein Altgerät die Mindestanforderungen nicht erfüllt, darf es für die Übergangsfrist - bis 31. März 2013 -

deutlich günstiger zu haben sei. Daraufhin zog der Verlag vor Gericht und bekam vor dem Amtsgericht München Recht. Die Frau wurde zur Zahlung der restlichen 491 EUR verdonnert. Die Münchner Richter begründeten dies damit, dass zur Berechnung der Lizenzgebühr nicht das billigste Angebot auf dem Markt zugrunde gelegt werden müsse. Für vergleichbare Karten würden auf dem Markt Preise zwischen 675 und 820 EUR erzielt. Daher sei die vom kartographischen Verlag verlangte Gebühr angemessen. Aufgrund der Urheberrechtsverletzung seien auch die Bearbeitungskosten von 79 EUR als Schadenersatz berechtigt.

Amtsgericht München, Az. 161 C 8713/09 vom 19.08.2009

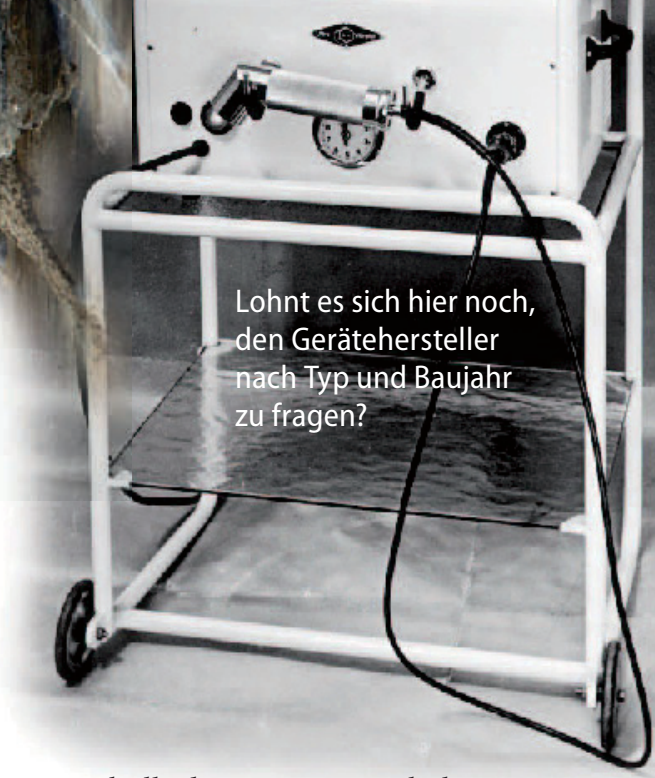

innerhalb der vertragsärztlichen Versorgung weiterverwendet werden. Aber: Die KV kann, nachdem sie die Meldung über den Typ und das Baujahr hat, für besonders alte Systeme schon früher den Anforderungsnachweis verlangen. (reh) Ärzte Zeitung, basierend auf www.kbv.de/ rechtsquellen/2488.html

\section{Arzt verurteilt Vorsicht beim Kinder-Notfall!}

Vorsicht bei der Behandlung von Kindern im Notdienst! Wer nicht altersgerecht dosierte Medikamente verabreicht, verletzt seine Berufspflichten.

Ein Internist hatte im Notdienst einer Zehnjährigen Metoclopramid (MCP) und Tramadol verabreicht. Da sich der Zustand des Mädchens daraufhin verschlimmerte, brachten die Eltern es in eine Klinik, wo es wegen des Verdachts auf extrapyramidale Nebenwirkungen behandelt wurde. In der Verhandlung gegen den Arzt wiesen Gutachter auf die Kontraindikation von MCP bis zum 14. Lebensjahr hin. Dem schloss sich das Gericht an und verhängte eine Geldbuße von 5500 EUR, weil er gegen die Regeln der ärztlichen Kunst verstoßen und eine dreifach überhöhte Dosis an MCP verabreicht habe.

OVG Nordrhein-Westfalen, Az. 6t A 2159/08 